\title{
On-field sports medicine emergencies: what's new!
}

Heinz Lohrer, ${ }^{1}$ Nikos Malliaropoulos ${ }^{2}$

\section{A major sports injury}

Last Saturday, after I completed a review for a scientific paper, I went out for what I planned as a relaxing mountain bike ride. The plan was to enjoy the Taunus highlands near my home in Frankfurt/ Main for $90 \mathrm{~min}$. However, $25 \mathrm{~min}$ into the ride, shortly after leaving the city and entering a wood I heard the siren of an ambulance as it approached from behind and passed by me. As I trailed the ambulance I wondered what might have happened and where. Another 5 min later, in a steep downhill trail the ambulance and I stopped and I leaned my mountain bike against a tree. In front of the ambulance (staffed with two paramedics), at the border of the trail in a curve, lay a cyclist prone against a tree stump with his right side. His friend had already removed his riding partner's helmet.

The patient was alert and conscious. However, he could not provide details of the accident or the injury mechanism. Initial examination was done without moving the patient. There were no obvious bleeding and head and spine were not tender. There was severe left shoulder pain as well as pain with inspiration. Meanwhile, an emergency physician arrived. While I manually fixed the patients shoulder region we (emergency physician, myself, two paramedics and the accompanying mountain biker) carefully put the patient in a (flexed) standing position. Then we sat and laid him down supine to a spine board. His clothes were cut and further examination revealed a clavicular fracture and a pneumothorax, both on the left side. His head and trunk were fixed to the spine board and the emergency physician initially inserted a cannula in the right cubital vein and provided him with analgesics and infusion. Then we put the patient inside the ambulance. He was intubated and a chest drain was put in to address his pneumothorax. Meanwhile, a mountain biker who was

\footnotetext{
${ }^{1}$ Institute for Sportsmedicine-Orthopaedic Department, Frankfurt, Hessen, Germany

${ }^{2}$ ECOSEP, Thessaloniki, Greece

Correspondence to Nikos Malliaropoulos, ECOSEP, ECOSEP G.Seferi 34, Harilaoy, Thessaloniki 54250, Greece; contact@sportsmed.gr
}

sent ahead to check the track reported that the track was stony but passable for the ambulance. When we finally arrived at the bottom of the valley, firemen had already blocked the road and we drove one more kilometre to where the rescue helicopter awaited us in a level paddock. The patient was in good condition and was transferred to the helicopter for hospital treatment.

This is an example of what can happen everyday to everyone, both as patient or as rescuer and it underscores BJSM's focus on various aspects of emergency sports medicine.

\section{In this issue}

Our case demonstrates that the clue to success following major sports injuries is initial survey and adequate prehospital care. Skill training is essential to optimise patient care rapidly as well as to avoid liability. Dr John Hanson reviews this field thoroughly in this issue (see page 1097).

In the case, there was no obvious head injury; however, concussion was in the differential diagnosis given the initial history. If these minor brain injuries happen in sport, the sportsman, his teammates and especially the coach/manager often demand the player return to play immediately because no injury is visible. Thus, the physician in charge bears the major responsibility of protecting the player's health. Renowned Australian neurologists Davis and Makdissi discuss how cognitive tests can help to solve the tension between wishing to participate in sport and the risk of worsening the injury by playing on. ${ }^{1}$

Probably, the helmet provided the mountain biker in our example from further head and brain injury. Current literature is clear with respect to the worth of wearing helmets in certain sports. However, the question which configuration of helmets provides maximum safety in an individual sport is not yet answered. Martin-Smith and colleagues (see page 1134) investigate the question, of whether helmets, while providing protection to the brain, lead to an increase in ear injuries. We note that it is essential to have rules to safely reintegrate an injured player into his sport and various papers provide somewhat differing suggestions. ECOSEP supports the Zurich Concussion Guidelines. ${ }^{2}$ We look at ways to improve the uptake of these guidelines (and their updated forth iteration). In last month's $B J S M$ Price suggested that adoption of the Zurich guidelines is not yet universal (http://bjsm.bmj.com/content/46/14/1000. full). ${ }^{3}$

Sudden cardiac arrest on the field is a rare, but sensational, event especially in top-level football. Thousands of spectators at the venue and literally millions of TV viewers may witness such an event. Sudden cardiac arrest has attracted specific focus from FIFA (see page 1094). Immediate resuscitation by well-trained staff is the key to increase the rate of survivors.

We note that historically, children were required or strongly advised to wear helmets and in the last decade the proportion of adult skiers wearing helmets has dramatically increased. The risk compensation hypothesis suggests that helmets promote more risky behaviour. Up to now there was no obligation for ski helmets. Collisions between helmeted and unhelmeted skiers increase the injury gravity of the unhelmeted party. The (rhetorical) question posed by the authors (see page 1091) calls for legislative support.

Finally, this BJSM issue also includes the outcome of an injury prevention programme for adult male amateur soccer players (see page 1114). This article reports one of the first studies among adult men. It adds to the body of literature around FIFA's 11 and $11+$ programmes and the authors underscore the need for compliance and fidelity with the proven programmes if players are to benefit.

\section{ECOSEP-A Europe-wide organisation welcomes you!}

In 2012, the Nobel Peace Prize was awarded to the European Union (EU). This indicates the international recognition of the continuing endeavour of the European countries to grow and succeed together. Especially remarkable in this context is the nonviolent 'revolution' which took place initially in Germany (breakdown of the Berlin wall) and later on in the 1990s when the Warsaw pact disaggregated. These unprecedented events provide tremendous inspiration for how we should embark on the 21 st century.

In this globalising world, SEM organisations must also come together. Common scientific and educational standards have to be developed to promote a high level of practical skills. EU national groups have some language barriers and we need to address this so that best practice is 
pan-European and not limited to one nation's view alone. Our personal experience is that the smaller the country, the better the international collaboration. Countries with larger populations, all speaking the same language, are under less pressure to cooperate internationally. For scientists for example, it is especially difficult to publish or lecture in a language different from their native tongue and therefore they are prone to take the 'easy way' of publishing in a national journal. As a result, many valuable insights do not reach the wider international audience even if published in a Medline-listed journal. This slows international knowledge exchange and progress.

ECOSEP - the European College of Sports and Exercise Physicians was founded to improve the care of sports people and promote public health in Europe through cooperation among physicians. Have you considered the benefits of ECOSEP? ECOSEP embraces a broad membership of SEM physicians, associated members particularly trainees in SEM and scientific contributors who teach relevant aspects of SEM from various disciplines. ECOSEP also welcomes medical students who wish to specialise in our growing and important specialty.

ECOSEP proposes to establish a mechanism whereby expertise in teaching and research can be shared particularly with those European communities where at present there is no appropriate background of expertise. The sports and exercise medicine physicians ECOSEP Travelling Fellowship is a great success and you can apply for 2013 on the website (http:// www.ecosep.eu). Other benefits of ECOSEP membership iclude sports medicine assessment and rehabilitation courses, and a very unique sports on field trauma emergencies course. Of course ECOSEP is a BJSM member society which means online journal access and support with the smorgasbord of digital education and news media that distinguishes BJSM.

\section{Put Frankfurt, 25-27 April 2013 in your calendar!}

One of the main European sports and exercise medicine physicians events is the ECOSEP Congress. This biannual, international, interdisciplinary event attracts participants (not only) from all over Europe. It is dedicated to sports medicine physicians, orthopaedic surgeons, general practitioners, podiatrists, podiatric surgeons, sports scientists, academics, researchers, physiotherapists and representatives from many contributing medical organisations. The next ECOSEP Congress will take place in Frankfurt from 25 to 27 April 2013. The congress is organised by the Frankfurt/ Main (Germany) Sports Medicine Institute under Professor Heinz Lohrer's leadership (http://www.ecosep-congress.eu/).

Internationally reknowned lecturers covering the whole field of SEM guarantee a high-quality scientific programme in both the plenary sessions and workshops.

\section{Scientific duathlon-for science and sport!}

During the ECOSEP Congress 2013 in Frankfurt/Main, Orhtotech will award their scientific duathlon prize for the first time. To win the prize young investigators have to present their papers orally or as posters and additionally they have to compete in a $6 \mathrm{~km}$ run. This unpreceded event underlines that SEM consists of both Sports and Science.

Enjoy this ECOSEP-shaped BJSM which higlights 'On-field sports medicine emergencies'. If you are a sports physician in Europe check the ECOSEP website and benefit from BJSM updates via the popular blog (http://blogs.bmj.com./ bjsm). Be among the over 60000 listeners to $B J S M$ podcasts (http://podcasts.bmj. com/bjsm). BJSM is easy to follow via Twitter(@BJSM_BMJ).

\section{Competing interests None.}

Provenance and peer review Commissioned; internally peer reviewed.

Received 16 October 2012

Accepted 16 October 2012

Br J Sports Med 2012;46:1089-1090.

doi:10.1136/bjsports-2012-091901

\section{REFERENCES}

1. Davis GA, Makdissi M. Concussion tests: clarifying potential confusion regarding sideline assessment and cognitive testing. Br J Sports Med 2012;46:959-60.

2. McCrory P, Meeuwisse W, Johnston K, et al. Consensus Statement on Concussion in Sport: the 3rd International Conference on Concussion in Sport held in Zurich, November 2008. Br J Sports Med 2009;43(Suppl 1):i76-90.

3. Price J, Malliaras P, Hudson Z. Current practices in determining return to play following head injury in professional football in the UK. Br J Sports Med 2012;46:1000-3. 